\section{Swamp cancer}

Hyphomycosis DESTRUENS EQUi, also called swamp cancer or bursattee, is a granulomatous disease commonly of the lower leg of the horse and is a well known condition in the tropics and subtropics'. The associated fungus, 'Hyphomyces destruens', has neither been legitimately described nor satisfactorily placed in any group of fungi except broadly in the Phycomycetes, on the grounds of the morphology of the hyphae in tissue and culture.

Following recent work in Australia by Johnston and Hutchin $s^{2}$, a request was made to these authors for isolates of the fungus from the New South Wales cases, but none had survived more than a few months in culture. This fate has also occurred to the isolates of Bridges and Emmons (H. Hasenclever, personal communication). In September 1973 isolates were obtained from four cases of swamp cancer in horses in the Central District of Papua New Guinea, which closely agreed with the limited description available of ' $\mathrm{H}$. destruens'.

Because of suggestions by Bridges and Emmons ${ }^{3}$ and by Amemiya and Nishiyama ${ }^{4}$ and its general resemblance to
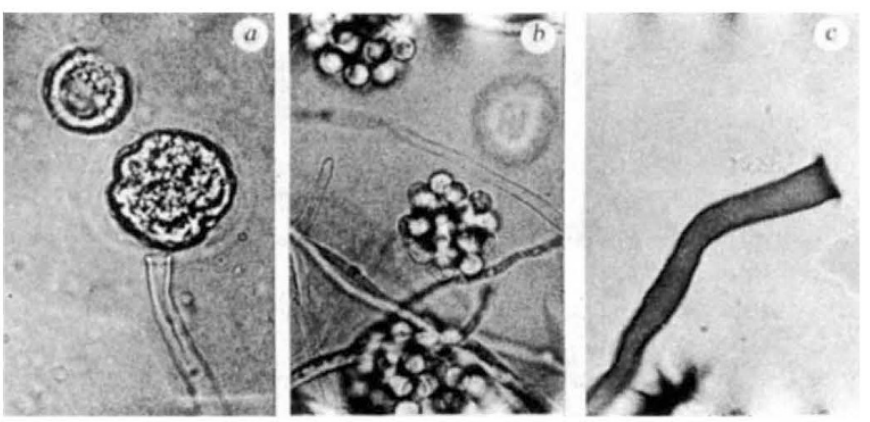

Fig. $1 a$, Rotating vesicle of sporangial contents undergoing cleavage into zoospores immediately after emission $(\times 270)$; $b$, zoospores encysted at sporangium apex $(\times 270) ; c$, sporangium aperture stained with Parker blue-black Quink $(\times 405)$.

Mortierella spp., a number of methods developed to encourage these fungi to produce sporangia were tried out on the cultures, for example, hay and silage agars, but without success. A further attempt was made by placing portions of colonies from a Sabouraud glucose agar plate in sterile water in a Petri dish, to which a small piece of sterilised rotten maize silage had been added. After incubation for $2 \mathrm{~d}$ at $25^{\circ} \mathrm{C}$ biflagellate zoospores $9-10 \mu \mathrm{m}$ diameter were noticed arising from the cleavage of protoplasmic masses emitted from undifferentiated filamentous sporangia (Fig. 1).

This behaviour shows that ' $\mathrm{H}$. destruens' is a Phycomycete belonging to the Pythiaceae in the Penonosporales and that it could be included in the genus Pythium Pringsheim ${ }^{5}$. Further work is in progress to establish whether it is a recognised or a new species, but the existence of a Pythium sp. pathogenic to mammals has not previously been suspected.

\section{P. K. C. Austwick}

Nuffield Institute of Comparative Medicine,

The Zoological Society of London,

Regent's Park, London, NWI, UK

\section{J. W. Copland}

Veterinary Research Laboratory,

PO Box 6372,

Boroko,

Papua New Guinea
Received April 1, 1974.

${ }^{1}$ de Haan, J., and Hoogkamer, L. J., Arch. wiss. prakt. Tierheilk., 29, 395 (1903).

2 Johnston, K. G., and Hutchins, D. R., Aust. vet. J., 48, 269 (1972).

${ }^{3}$ Bridges, C. H., and Emmons, C. W., J. Am. vet. med. Ass., 138, 579 (1961).

${ }^{4}$ Amemiya, J., and Nishiyama, S., Bull. Fac. Agric. Kagoshima Univ., 17, 215 (1966).

'Waterhouse, G. M., Mycol. Pap., 110, 1 (1968).

\section{Erratum}

IN the letter "Appearance of unusual mitochondria in rice coleoptiles at conditions of secondary anoxia" by B. B. Vartapetian, I. N. Andreeva and A. L. Kursanov (Nature, 248,258 ; 1974) the wrong illustration was published as Fig. 1d. The bottom half of Fig. 1 should be:

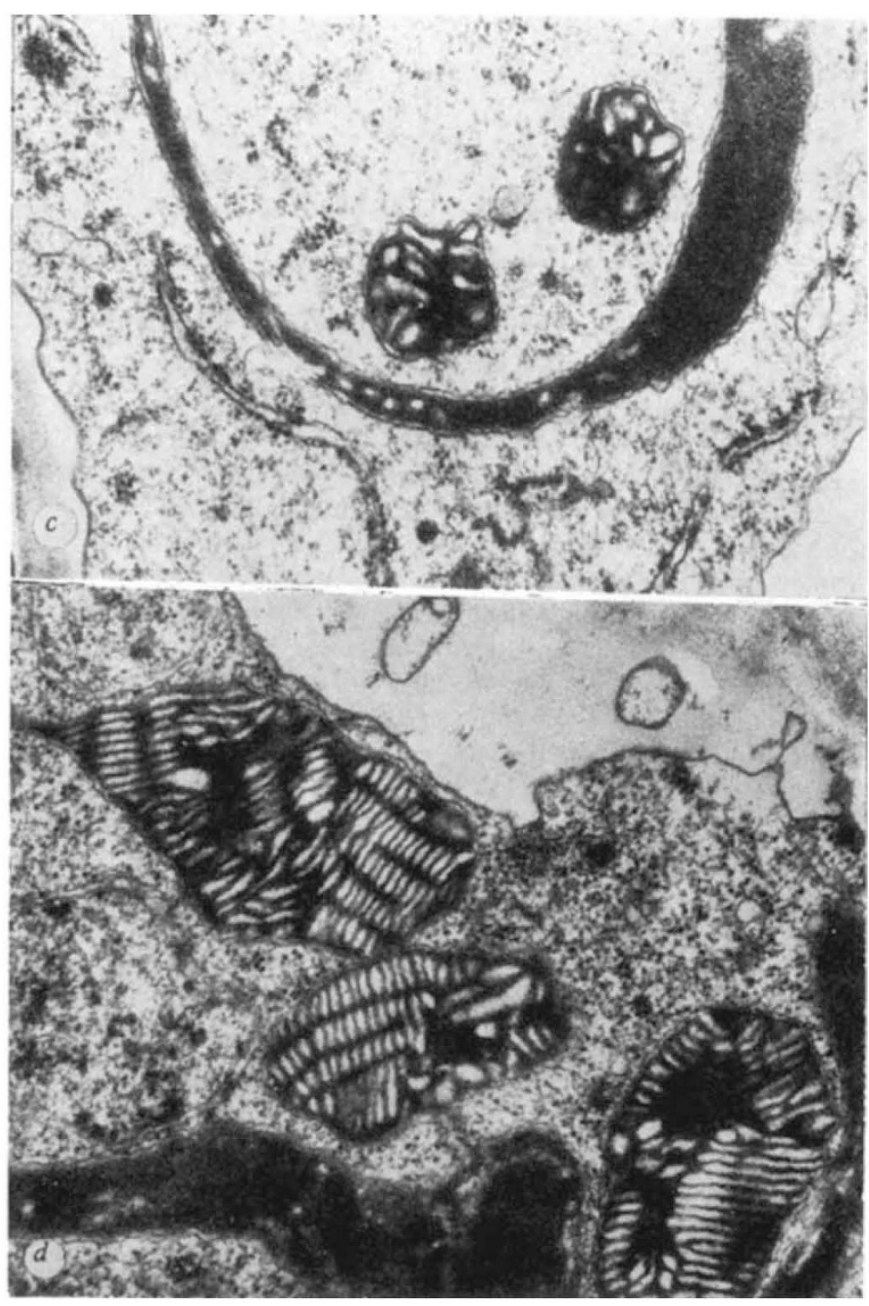

Fig. 1 Ultrastructure of mitochondria in cells of rice roots and coleoptiles in aerobic and anaerobic conditions. $a$, Root, $9 \mathrm{~d}$ after growth in aerobic conditions; $b$, root, $6 \mathrm{~d}$ of aerobic growth, then $3 \mathrm{~d}$ of growth in anaerobic conditions; $c$, coleoptile, $9 \mathrm{~d}$ of aerobic growth; $d$, coleoptile, $6 \mathrm{~d}$ of aerobic growth, then $5 \mathrm{~d}$ of growth in anaerobic conditions. 